\title{
P0191
}

\section{REAL ENVIRONMENT RESEARCH LABORATORY WITH LIGHT POLLUTION OPTIMIZED STREET LIGHTING LUMINAIRES}

Ferenc Szabó et al.

DOI 10.25039/x46.2019.PO191

from

CIE x046:2019

Proceedings

of the

29th CIE SESSION

Washington D.C., USA, June 14 - 22, 2019

(DOI 10.25039/x46.2019)

The paper has been presented at the 29th CIE Session, Washington D.C., USA, June 14-22, 2019. It has not been peer-reviewed by CIE.

\section{(C) CIE 2019}

All rights reserved. Unless otherwise specified, no part of this publication may be reproduced or utilized in any form or by any means, electronic or mechanical, including photocopying and microfilm, without permission in writing from CIE Central Bureau at the address below. Any mention of organizations or products does not imply endorsement by the CIE.

This paper is made available open access for individual use. However, in all other cases all rights are reserved unless explicit permission is sought from and given by the CIE.

CIE Central Bureau

Babenbergerstrasse 9

A-1010 Vienna

Austria

Tel.: +43 17143187

e-mail: ciecb@cie.co.at

www.cie.co.at 


\title{
REAL ENVIRONMENT RESEARCH LABORATORY WITH LIGHT POLLUTION OPTIMIZED STREET LIGHTING LUMINAIRES
}

\author{
Szabó, F., Csuti, P., Kolláth, Z. \\ ${ }^{1}$ LightingLab Calibration Laboratory, Veszprém, HUNGARY, ${ }^{2}$ Eötvös Loránd University, \\ Szombathely, HUNGARY \\ info@lightinglab.eu
}

DOI 10.25039/x46.2019.PO191

\begin{abstract}
Light pollution is a growing problem for the natural environment, but also for human health. More and more international surveys show that blue radiation content of certain (mostly cool white) LED lighting increases the risk of some illness compared to earlier orange-yellow sodium lamps. This is one of the reasons why some of today's laptops and mobile phones are already set to decrease CCT (and blue content of the radiation) after sunset. Lighting trends of the last decade have been favoured by LED technology based on phosphor converting technology, which means significant emission in the $430 \mathrm{~nm}-480 \mathrm{~nm}$ wavelength range where our intrinsically photosensitive ganglion cells (ipRGCs) are the most sensitive. As a consequence of Rayleigh scattering, short wavelength photons are the most efficiently scattering photons, 9,4 times more efficient as the scattering of $700 \mathrm{~nm}$ photons. As an experience of LED public lighting projects of the last decade, public lighting strategy is moving nowadays to warm white LEDs and Amber LED-based solutions.
\end{abstract}

Keywords: Light Pollution, tuneable LED street lighting, Dark Sky Parks

\section{Introduction}

As the wide expand of LED street lighting, light pollution became a concern not only for lighting designers, but also astronomers, biologists. Previously, the accepted upper limit of the correlated colour temperature (CCT) was $4000 \mathrm{~K}$. However, studies have shown, that by the spreading of cool white LEDs, the high-intensity blue peak of their spectral power distribution has a harmful effect to the living environment and ecosystem. The latest studies (Garcia-Saenz et al. 2018) have described a direct correlation between the colour of public lighting and tumour formation, e.g. in breast, prostate and colorectal cancers. Definition of light pollution according to the International Lighting Vocabulary is the following:

Any light emitted in an improper direction (according to the given application) means not only waste of energy for the provider of public lighting and the community, but also significant negative effects on the hormone system of birds and insects. The artificial gloss of sky around urban areas obstructs astronomers at their investigations, and inhabitants could have difficulties with the perception of stars and the Milky Way.

Measurements and numerical radiation transfer simulations of an earlier lighting remodelling (Kolláth et al. 2016) demonstrated that the level of light pollution can be significantly reduced with the right spectral composition of the sources. Very recently Aubé et al. (2018) calculated the effect of the conversion to white LED lighting at a dark sky place.

International Dark Sky Association (IDA) has strict regulations for Dark Sky Park areas to be fulfilled within 5 and 10 years after registered as Dark Sky Park in a framework of a mandatory Lighting Master Plan.

Basic requirements are the following

(https://www.darksky.org/wp-content/uploads/2018/12/IDSP-Guidelines-2018.pdf): 
- $\mathrm{CCT}<3000 \mathrm{~K}$,

- the energy radiation under the wavelength of $550 \mathrm{~nm}$ must not exceed $25 \%$ of the total radiated energy of the light source

- $\mathrm{S} / \mathrm{P}$ ratio $<1,3$.

Endeavours to reduce light pollution has only been realised in the form of pilot projects at some places in the world (https://www.forbes.com/sites/jeffkart/2018/05/23/dark-sky-friendlylighting-lets-you-see-the-stars/\#72a9c2e7c3e8, http://ricemm.org/en/2014/03/), by using amber LED lights.

In Hungary, there are three areas, which are registered as International Dark Sky Park by IDA: Hortobágy National Park (since 2011), Zselic (since 2009) and Bükk (since 2017) Dark Sky Parks.

As one of the first developments of a Hungarian National Project (EFOP-3.6.2-16-201-00014), open air, real environment research laboratories have been established both in the Zselic and Bükk Dark Sky Parks, by a total reconstruction of the street lighting of two villages. Reconstruction has been done by the installation of custom developed, innovative LED street lighting luminaires.

In the real environment research laboratory, the effects of artificial light on fauna and inhabitants can be studied.

\section{Method}

Two aspects were considered during the design:

Recent research has shown that cool white light is harmful to the environment and to the human health and species of fauna and flora. Therefore, in designing the new public lighting, the primary consideration was to emit only warm white light with minimal blue radiation. In addition, on the side streets after $10 \mathrm{pm}$, the lights of the public lighting are weakened (according to the reduced traffic) and then only the biologically optimal amber yellow light illuminates. This capability is realized by specially developed spectrally tuneable LED public lighting luminaires. Further innovative content of the system is that the different LED channels have different lens optics as well. Thanks to that, the spatial distribution of light output can be optimized as well for different needs of public lighting at night hours. An innovative control system translates the given schemes into LED current values at the luminaires. This solution is a novelty in the world as well.

Another aspect was to totally exclude any light output at $90^{\circ}$ and above (ULOR=0). This also helps to improve and maintain the status of the sky in two Starry Sky Parks in Central Europe affected by settlements and gives a liveable environment for village residents at the same time.

At the moment of joining IDA Dark Sky Park list, street lighting of two villages Bárdudvarnok at Zselic and Répáshuta at Bükk mountains was realized with fluorescent lamps and High Pressure Sodium lamps. Outdated luminaire bodies caused a significant light output above the horizon, while illuminance values and homogeneity of the road surface illuminance have not fulfilled the requirements EN 13 201:2016 standard.

Table 1 - IDA requirements for Dark Sky Parks and parameters of the old street lighting system at Bükk and Zselic

\begin{tabular}{|l|l|l|l|l|}
\hline & \multicolumn{1}{|c|}{$\begin{array}{c}\text { IDA } \\
\text { requirements }\end{array}$} & \multicolumn{1}{|c|}{$\begin{array}{c}\text { old system } \\
(\mathrm{CFL})\end{array}$} & $\begin{array}{c}\text { new system } \\
\text { evening, } \\
\text { morning mode }\end{array}$ & $\begin{array}{c}\text { New system } \\
\text { night mode }\end{array}$ \\
\hline Power at $<550 \mathrm{~nm}$ & $25 \%$ & $46 \%$ & $19 \%$ & $5 \%$ \\
\hline S/P ratio & 1,3 & 1,3 & 0,9 & 0,44 \\
\hline $\mathrm{CCT}$ & $3000 \mathrm{~K}$ & $3600 \mathrm{~K}$ & $2400 \mathrm{~K}$ & $1900 \mathrm{~K}$ \\
\hline
\end{tabular}


In order to develop an innovative street lighting solution for Dark Sky Parks, ELTE SEK subcontracted a Hungarian LED Street Lighting manufacturer company and an independent accredited laboratory for the total control of the development phases.

Conception of decreasing light pollution and fulfil IDA requirements contained the following ideas:

- achieve ULOR=0 with custom designed PMMA optics lenses and special shield

- using of two different lenses for two different light intensity distribution evening/morning period (wide beam) and night period (narrow beam)

- using of two different LED types for two different light colour at evening/morning period (WW $3000 \mathrm{~K}$ ) and night period (Pc-Amber $2200 \mathrm{~K}$ )

- using an intelligent light profile controller to realize two light profiles
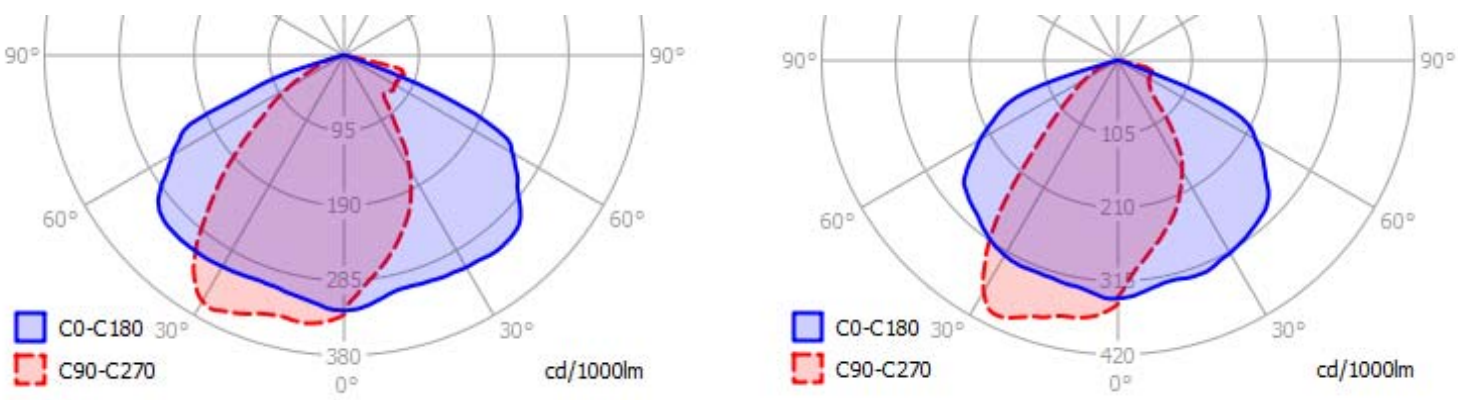

Figure 1 - Light Intensity Distribution of evening mode (left) and night mode (right) profiles.
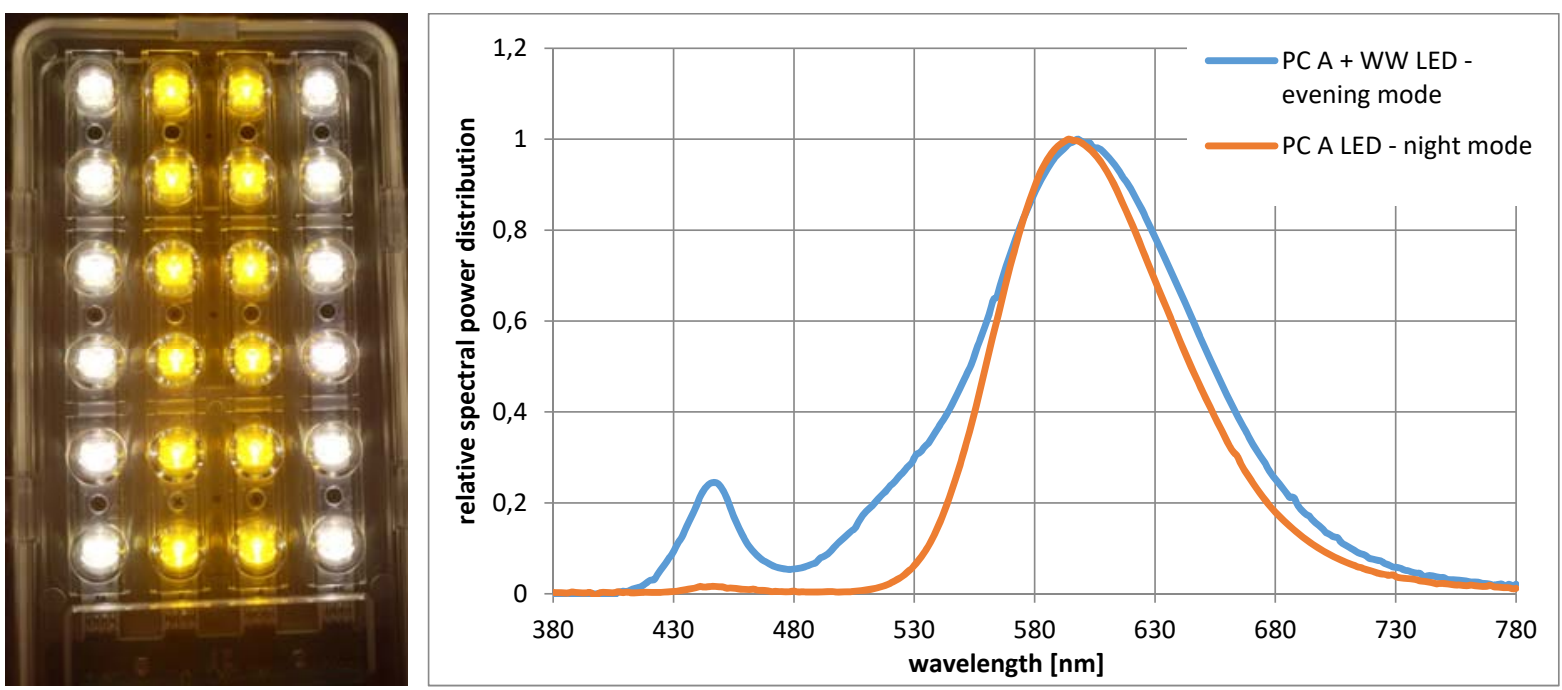

Figure 2 - Spectral Power Distribution of evening and night profiles.

\section{Measurement results}

As a continuous communication among astronomers, lamp manufacturer and laboratory, a control protocol has been developed for the project. After each checkpoint, investigation results and development suggestions have been sent to all the members of the team as actual state conclusions.

Measurements during the project have been done partly as laboratory measurements: 
- gonio photometry of prototype luminaire

- investigation of electrical parameters

- investigation of spectral and colorimetric parameters

In order to compare the before-after state, illuminance measurements on the roads and sky luminance measurements had been done. On-site measurements have been done as:

- illuminance measurements of selected areas before reconstruction

- illuminance measurements of selected areas after reconstruction

- luminance measurements before reconstruction

- luminance measurements after reconstruction

After the installation of the developed luminaires, a public survey has been started and opinions of residents have been collected at both venues.

\subsection{Laboratory Investigations}

LED luminaire has been investigated according to a pre-declared protocol at two phases: first prototype and a final prototype have been investigated.

Both, first and final prototype luminaires have been investigated at two different operation profiles.

Light Intensity Distribution has been measured with the help of a double mirror goniophotometer in order to investigate ULOR parameter. A power analyser has been applied to evaluate electrical parameters of the luminaires, while spectral properties have been measured with a spectral irradiance meter according to IESNA LM-79.

IDA requirements for Dark Sky Parks have been controlled for the project prototype luminaires, results can be seen in Table 1. The a-opic values of the old and new public lighting have been evaluated from spectral data. $\alpha$-opic values can be seen in Table 2.

Table 2 - Results of laboratory investigations of the final prototype

\begin{tabular}{|c|c|c|c|}
\cline { 2 - 4 } \multicolumn{2}{c|}{} & $\begin{array}{c}\text { night mode } \\
\text { (PC Amber) }\end{array}$ & $\begin{array}{c}\text { evening mode } \\
\text { (WW+PC Amber) }\end{array}$ \\
\hline \multirow{2}{*}{ Voltage } & Nominal & $230,00 \mathrm{~V}$ & $230,00 \mathrm{~V}$ \\
\cline { 2 - 4 } & Actual & $230,12 \mathrm{~V}$ & $230,01 \mathrm{~V}$ \\
\hline \multicolumn{2}{|c|}{ CIE CRI $\left(R_{\mathrm{a}}\right)$} & $1861 \mathrm{~K}$ & $2402 \mathrm{~K}$ \\
\hline \multirow{2}{*}{ CIE } & 0,0070 & 0,0022 \\
\hline \multirow{2}{*}{$\begin{array}{c}\text { CIE } 1931 \text { colour } \\
\text { coordinates }\end{array}$} & $x$ & 42,0 & 68,9 \\
\cline { 2 - 4 } & $y$ & 0,5596 & 0,4905 \\
\hline
\end{tabular}

Table 3 - $\alpha$-opic values of the old and new public lighting.

\begin{tabular}{|c|c|c|c|c|c|c|}
\hline & & $\begin{array}{c}\text { S-cone- } \\
\text { opic }\end{array}$ & $\begin{array}{c}\text { M-cone- } \\
\text { opic }\end{array}$ & L-cone-opic & Rhodopic & Melanopic \\
\hline $\begin{array}{c}\text { evening } \\
\text { mode }\end{array}$ & $\alpha$-opic ELR & 0,154 & 1,065 & 1,664 & 0,540 & 0,358 \\
\cline { 2 - 7 } & $\alpha$-opic DER & 0,189 & 0,732 & 1,022 & 0,373 & 0,270 \\
\hline \multirow{2}{*}{$\begin{array}{c}\text { night } \\
\text { mode }\end{array}$} & $\alpha$-opic ELR & 0,013 & 0,927 & 1,702 & 0,263 & 0,104 \\
\cline { 2 - 7 } & $\alpha$-opic DER & 0,016 & 0,637 & 1,045 & 0,181 & 0,078 \\
\hline
\end{tabular}




\subsection{On-site Investigations}

For the illuminance measurements, 4 representative pole to pole areas have been selected at Bárdudvarnok and 7 representative pole to pole areas have been selected at Répáshuta, where no chance of shadows are present.

Measurements were done with a special road illuminance meter device, applying three calibrated photodetectors, each having $f_{1}{ }^{\prime}<1,5$. Measurement points have been selected according to EN 13201 standard.

Figure 3 shows the on-site illuminance measurement results of a typical pole to pole area at Bárdudvarnok in three situations: before reconstruction (CFL), after reconstruction (evening and night modes). Because of content limits, only one typical pole to pole area is presented.

Before (CFL) static street lighting system
After (WW + PCA LED) evening mode
After (PCA LED) night mode

\begin{tabular}{|c|c|c|c|c|c|c|c|c|}
\hline$d[\mathrm{~m}]$ & \multicolumn{3}{|c|}{$\downarrow$} & & \multicolumn{3}{|c|}{$\uparrow$} & \\
\hline 1,4 & 1,12 & 1,03 & 1,4 & 1,66 & 1,85 & 2,74 & \\
\hline 4,2 & 1,22 & 1,03 & 1,4 & 1,6 & 1,74 & 2,43 & \\
\hline 7,1 & 1,32 & 1,03 & 1,5 & 1,54 & 1,54 & 2,13 & \\
\hline 10 & 1,22 & 0,92 & 1,3 & 1,37 & 1,23 & 1,83 & \\
\hline 12,8 & 1,12 & 0,92 & 1,2 & 1,26 & 1,11 & 1,63 & \\
\hline 15,6 & 1,32 & 1,03 & 1,3 & 1,4 & 1,23 & 1,73 & \\
\hline 18,5 & 1,53 & 1,23 & 1,6 & 1,81 & 1,74 & 2,23 & \\
\hline 21,3 & 1,42 & 1,23 & 1,6 & 1,75 & 1,74 & 2,33 & \\
\hline 24,1 & 1,42 & 1,23 & 1,7 & 1,96 & 2,15 & 2,84 & \\
\hline 27 & 1,32 & 1,23 & 1,7 & 2,18 & 2,46 & 3,44 & \\
\hline
\end{tabular}

\begin{tabular}{|c|c|c|c|c|c|c|c|}
\hline$d[m]$ & \multicolumn{3}{|c|}{$\downarrow$} & \multicolumn{3}{c|}{$\uparrow$} & \\
\hline 1,4 & 5,46 & 5,99 & 7,23 & 13 & 15,9 & 23,6 & \\
\hline 4,2 & 6,19 & 6,92 & 8,44 & 13,4 & 15,4 & 21,7 & \\
\hline 7,1 & 5,9 & 6,54 & 7,42 & 8,98 & 9,82 & 12,8 & \\
\hline 10 & 4,95 & 5,32 & 5,71 & 5,87 & 7,18 & 8,77 & \\
\hline 12,8 & 5,48 & 5,46 & 5,53 & 5,92 & 6,61 & 7,58 & \\
\hline 15,6 & 6,11 & 6,02 & 6,23 & 7,16 & 7,65 & 8,69 & \\
\hline 18,5 & 6,66 & 6,81 & 7,41 & 9,06 & 9,78 & 11,5 & \\
\hline 21,3 & 8,34 & 8,49 & 9,79 & 13 & 14,5 & 17,9 & \\
\hline 24,1 & 8,53 & 9,25 & 11,3 & 16,6 & 19,5 & 27,3 & \\
\hline 27 & 6,95 & 7,68 & 9,36 & 13,7 & 16,6 & 24,3 & \\
\hline
\end{tabular}

\begin{tabular}{|c|c|c|c|c|c|c|c|}
\hline$d[m]$ & \multicolumn{3}{|c|}{$\downarrow$} & \multicolumn{3}{c|}{$\uparrow$} & \\
\hline 1,4 & 3,06 & 3,06 & 3,52 & 4,77 & 5,77 & 7,68 & $L$ \\
\hline 4,2 & 3,21 & 3,25 & 3,56 & 4,14 & 4,88 & 2,71 & \\
\hline 7,1 & 2,42 & 2,41 & 2,43 & 2,78 & 3,12 & 3,63 & \\
\hline 10 & 2,03 & 2 & 1,92 & 2,16 & 2,45 & 2,69 & \\
\hline 12,8 & 1,13 & 1,96 & 1,83 & 1,91 & 2,27 & 2,33 & \\
\hline 15,6 & 2,14 & 2,01 & 1,92 & 2,18 & 2,44 & 2,51 & \\
\hline 18,5 & 2,39 & 1,79 & 2,18 & 2,46 & 2,83 & 3,1 & \\
\hline 21,3 & 3,38 & 3,02 & 3,13 & 3,6 & 4,04 & 4,55 & \\
\hline 24,1 & 3,78 & 3,67 & 4,14 & 5,16 & 5,66 & 7,21 & \\
\hline 27 & 3,57 & 3,73 & 4,31 & 5,2 & 6,02 & 8,03 & $L$ \\
\hline
\end{tabular}

\begin{tabular}{|c|c|c|c|l|l|l|l|}
\hline E & \multicolumn{3}{|c|}{1,29} & & \multicolumn{3}{c|}{1,89} \\
\hline Emin & \multicolumn{3}{|c|}{0,92} & & \multicolumn{3}{c|}{1,11} \\
\hline$U_{0}$ & \multicolumn{2}{|c|}{0,72} & & \multicolumn{3}{c|}{0,59} \\
\hline Mean & 1,3 & 1,09 & 1,47 & & 1,66 & 1,68 & 2,33 \\
\hline$u_{0}$ & 0,85 & 0,88 & 0,87 & & 0,76 & 0,68 & 0,68 \\
\hline$u_{1}$ & 0,86 & 0,85 & 0,82 & & 0,76 & 0,66 & 0,7 \\
\hline$u_{2}$ & 0,74 & 0,75 & 0,71 & 0,58 & 0,45 & 0,47 \\
\hline
\end{tabular}

\begin{tabular}{|c|c|c|c|c|c|c|c|}
\hline E & \multicolumn{3}{|c|}{7,05} & & \multicolumn{3}{c|}{13,11} \\
\hline Emin & \multicolumn{2}{|c|}{4,95} & & \multicolumn{3}{c|}{5,87} \\
\hline$U_{0}$ & \multicolumn{2}{|c|}{0,7} & & \multicolumn{3}{c|}{0,45} \\
\hline Mean & 6,46 & 6,85 & 7,84 & & 10,7 & 12,3 & 16,4 \\
\hline$u_{0}$ & 0,76 & 0,74 & 0,7 & & 0,64 & 0,63 & 0,6 \\
\hline$u_{1}$ & 0,77 & 0,78 & 0,71 & 0,55 & 0,54 & 0,46 \\
\hline$u_{2}$ & 0,58 & 0,58 & 0,49 & 0,35 & 0,34 & 0,28 \\
\hline
\end{tabular}

\begin{tabular}{|c|c|c|c|c|c|c|}
\hline$E$ & \multicolumn{3}{|c|}{2,77} & \multicolumn{3}{|c|}{3,94} \\
\hline Emin & \multicolumn{3}{|c|}{1,13} & \multicolumn{3}{|c|}{1,91} \\
\hline $\mathrm{U}_{0}$ & \multicolumn{3}{|c|}{0,41} & \multicolumn{3}{|c|}{0,48} \\
\hline Mean & 2,71 & 2,69 & 2,89 & 3,44 & 3,95 & 4,45 \\
\hline$u_{0}$ & 0,72 & 0,72 & 0,67 & 0,66 & 0,66 & 0,55 \\
\hline $\mathrm{u}_{1}$ & 0,42 & 0,67 & 0,63 & 0,55 & 0,58 & 0,52 \\
\hline $\mathrm{u}_{2}$ & 0,3 & 0,48 & 0,43 & 0,37 & 0,38 & 0,29 \\
\hline
\end{tabular}

Figure 3 - Summary of illuminance measurement results at Zselic, $E_{h}[I x]$ (left: before, middle: after - PCA + WW LED, right: after - PCA LED) 

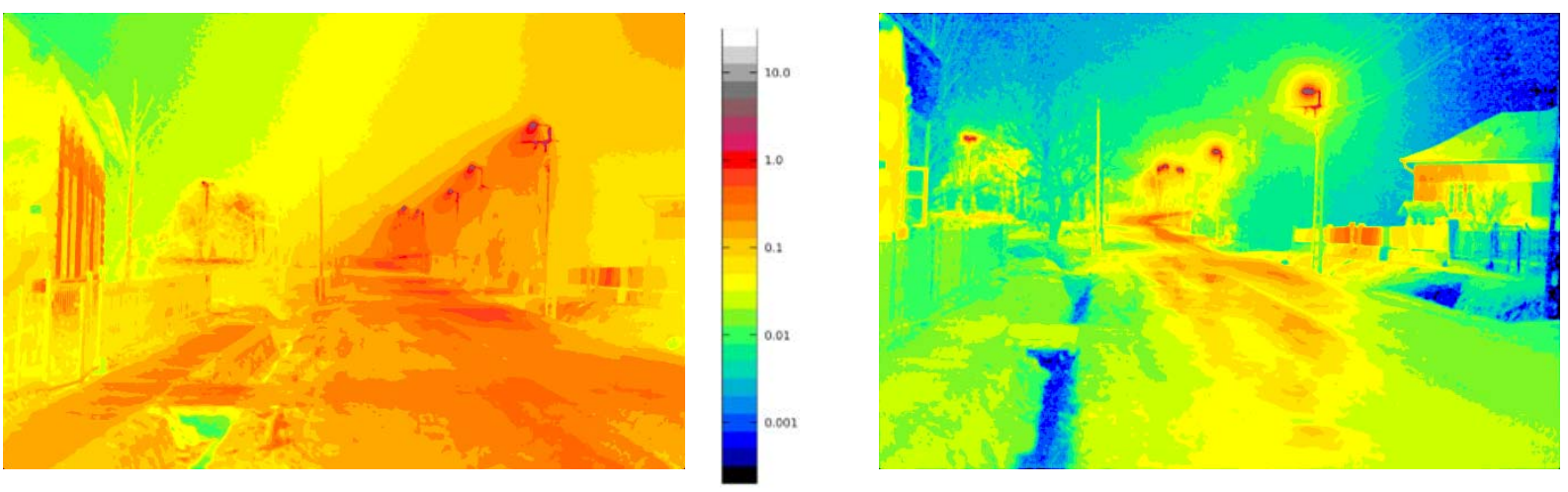

Figure 4 - Imaging luminance measurement results at Zselic, $E_{h}[1 x]$ (left: before, right: after - WW+PCA LED)

We developed a software package (DiCaLum) based on GNU Octave to process digital camera raw images for imaging photometry and radiometry (Kolláth \& Dömény 2017). Although this program is mostly used for night sky quality measurement, it can be used for absolute road luminance measurements. We performed road measurements with this system and our standard camera/lens combination; the results are displayed in Figure 4.

As it can be seen in Figure 4, both absolute luminance of the road surface and luminance homogeneity of the road surface has been significantly improved.

\section{Discussion}

Laboratory investigations of project final prototype showed, that ULOR $=0$ is satisfied. Electrical parameters of the luminaire in all operating modes fulfil criteria of the requirements published by the Hungarian Lighting Association for street lighting luminaires. Luminous efficacy in PC-Amber mode is significantly low compared to typical phosphor white LED street lighting luminaires. This fact relates to available phosphor converting amber LED technology in early 2018. By the submission of this manuscript, an increase of $30 \%$ had been reached.

Spectral power distribution analysis showed that the old street lighting system had not fulfilled IDA requirements for Dark Sky Parks, while after reconstruction the new LED street lighting fulfils all the criteria at the same time in each operation mode.

a-opic values of the new public lighting shows satisfying melanopic values.

On-site illuminance measurements have shown, that average illuminance levels significantly increased, homogeneity of road illumination mostly increased but never decreased significantly at the investigated pole to pole areas.

\section{Conclusion}

One of the most important conclusions, that it is possible to create minimal light pollution public lighting compared to traditional high pressure sodium public lighting installations, which provides a safe and liveable environment of residents at the same time. All the IDA requirements for Dark Sky Parks can be fulfilled at the same time. In order to keep luminous efficacy of such LED street lighting at a feasible value, excellent lens and luminaire design, addition of phosphor white LEDs were needed. By springtime 2019, luminous efficacy of PcAmber LEDs improved by $30 \%$ compared to LEDs had been applied in the project luminaires. These two real environment laboratories will host more scientific investigations in the future. With the improvement of phosphor amber LED technology, further advantages on energy efficiency can be reached.

\section{Acknowledgement}

This work was supported by the grant no. EFOP-3.6.2-16-201-00014 of the European Union and co-financed by the European Social Fund. 


\section{References}

Garcia-Saenz A, Sánchez de Miguel A, Espinosa A et al. (2018) Evaluating the association between artificial light-at-night exposure and breast and prostate cancer risk in Spain (MCC-Spain study). Environmental Health

Perspectives 126(4):47011(https://doi.org/10.1289/EHP1837)

Poppe A, Szalai A, Parry J (2012) Advanced thermal characterization improves LED streetlight design. LEDs Magazine, July/August 2012

Kolláth, Z, Dömény, A, Kolláth, K \& Nagy, B (2016) Qualifying lighting remodelling in a Hungarian city based on light pollution effects Journal of Quantitative Spectroscopy and Radiative Transfer. 181:46 https://doi.org/10.1016/j.jqstt.2016.02.025

Kolláth, Z, \& Dömény, A (2016) Night sky quality monitoring in existing and planned dark sky parks by digital cameras, International Journal of Sustainable Lighting. 19(1):61 https://doi.org/10.26607/ijsl.v19i1.70

Aubé, M.; Simoneau, A.; Wainscoat, R.; Nelson, L. (2018) Modeling the effects of phosphor converted LED lighting to the night sky of the Haleakala Observatory, Hawaii, Monthly Notices of the Royal Astronomical Society, 478:1776 